\title{
A Bisboronic Acid Sensor for Ultra-high Selective Glucose Assay by
}

\section{${ }^{19}$ F NMR Spectroscopy}

Xu-dong Gao, ${ }^{1,2}$ Xin-zhen $\mathrm{Du}^{{ }^{*}}$ and Yan-ping Shi, ${ }^{2^{*}}$

${ }^{1}$ College of Chemistry and Chemical Engineering, Northwest Normal University, Lanzhou 730070, People's Republic of China, Email: duxz@nwnu.edu.cn

${ }^{2}$ CAS Key Laboratory of Chemistry of Northwestern Plant Resources, Lanzhou Institute of Chemical Physics, Chinese Academy of Sciences (CAS), Lanzhou 730000, People's Republic of China, Email: shiyp@licp.cas.cn

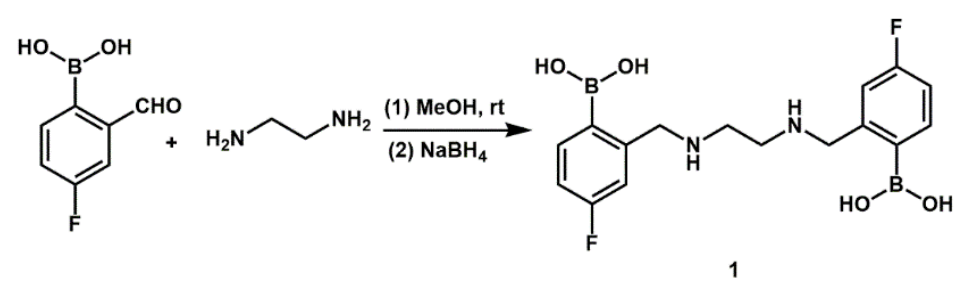

Scheme S1. Synthesis of N, N'-bis (2-boronic acid benzyl-4-fluoro) ethylenediamine (sensor 1). The detailed synthesis procedures were presented in the article.

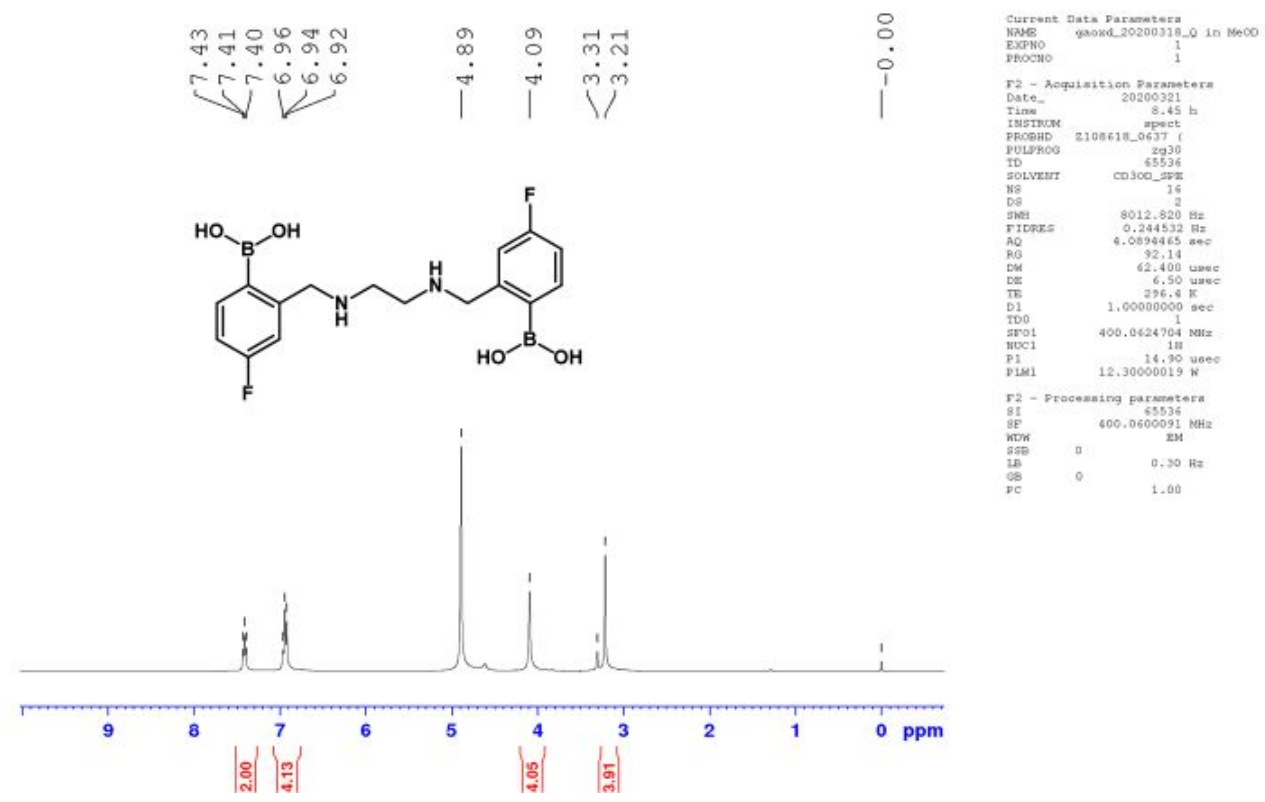

Figure S1. ${ }^{1} \mathrm{H}$ NMR (400 MHz, MeOD) spectrum of sensor 1 

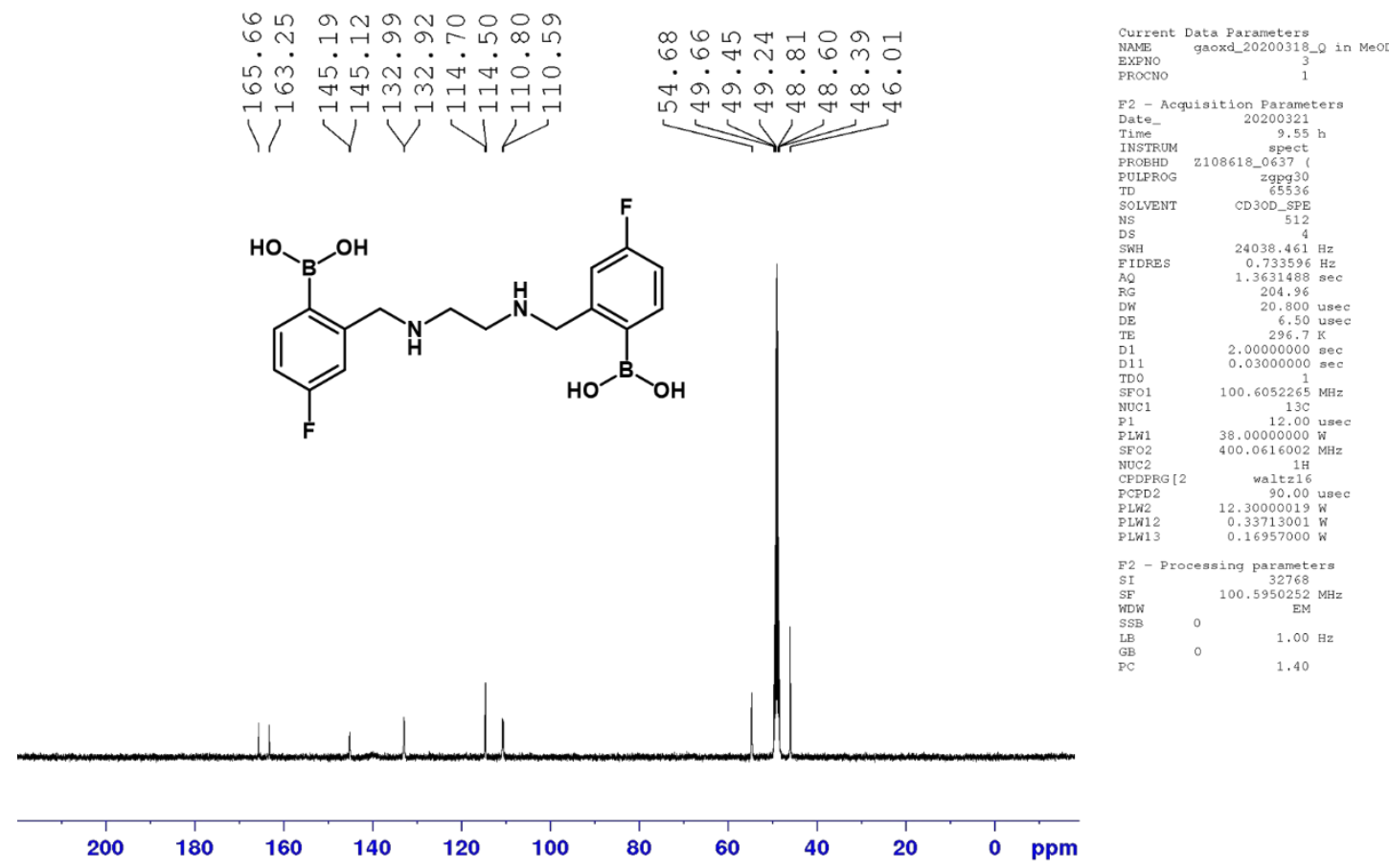

Figure S2. ${ }^{13} \mathrm{C} \mathrm{NMR}(100 \mathrm{MHz}, \mathrm{MeOD})$ spectrum of sensor 1
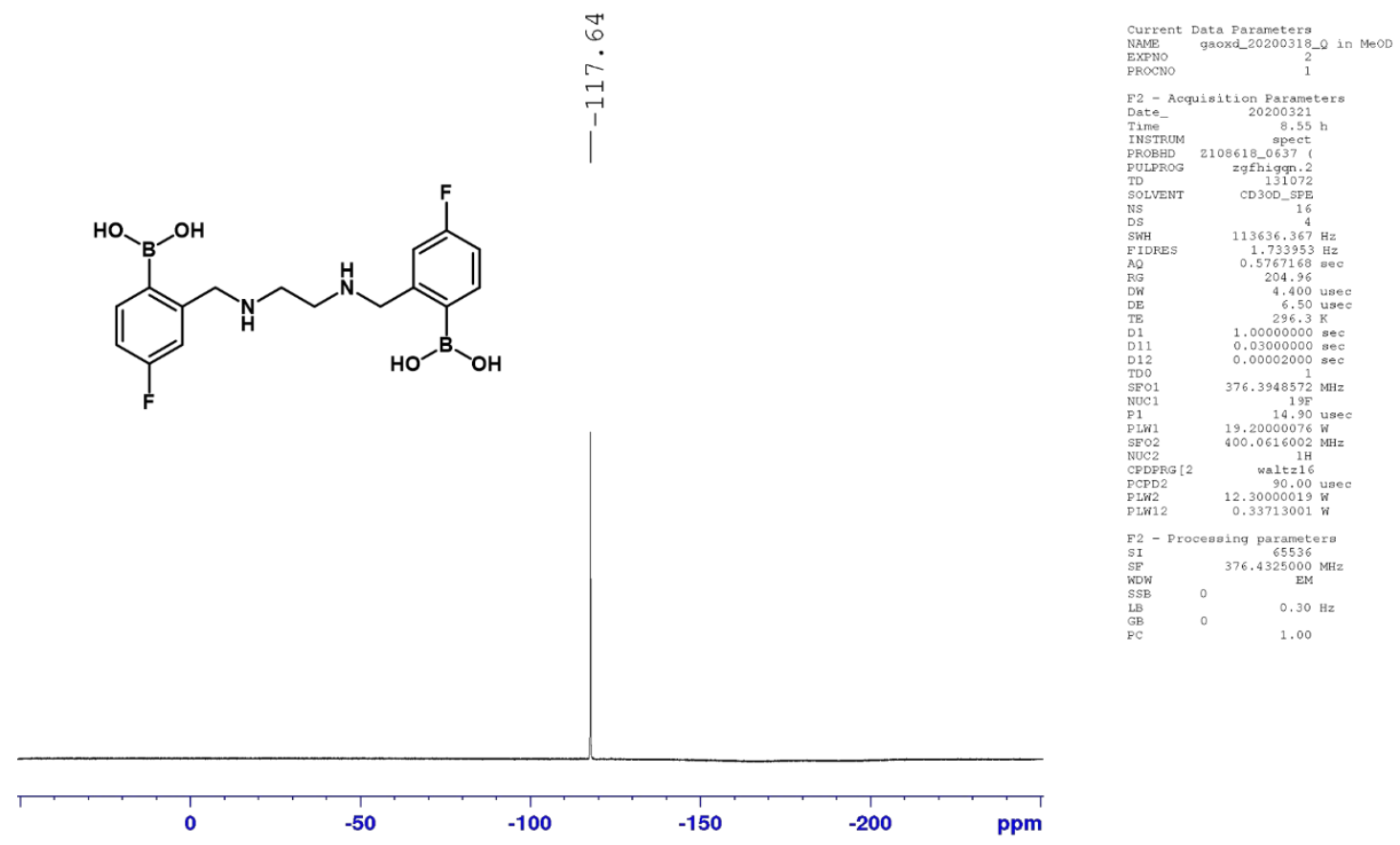

Figure S3. ${ }^{19} \mathrm{~F}$ NMR (376 MHz, MeOD) spectrum of sensor 1 


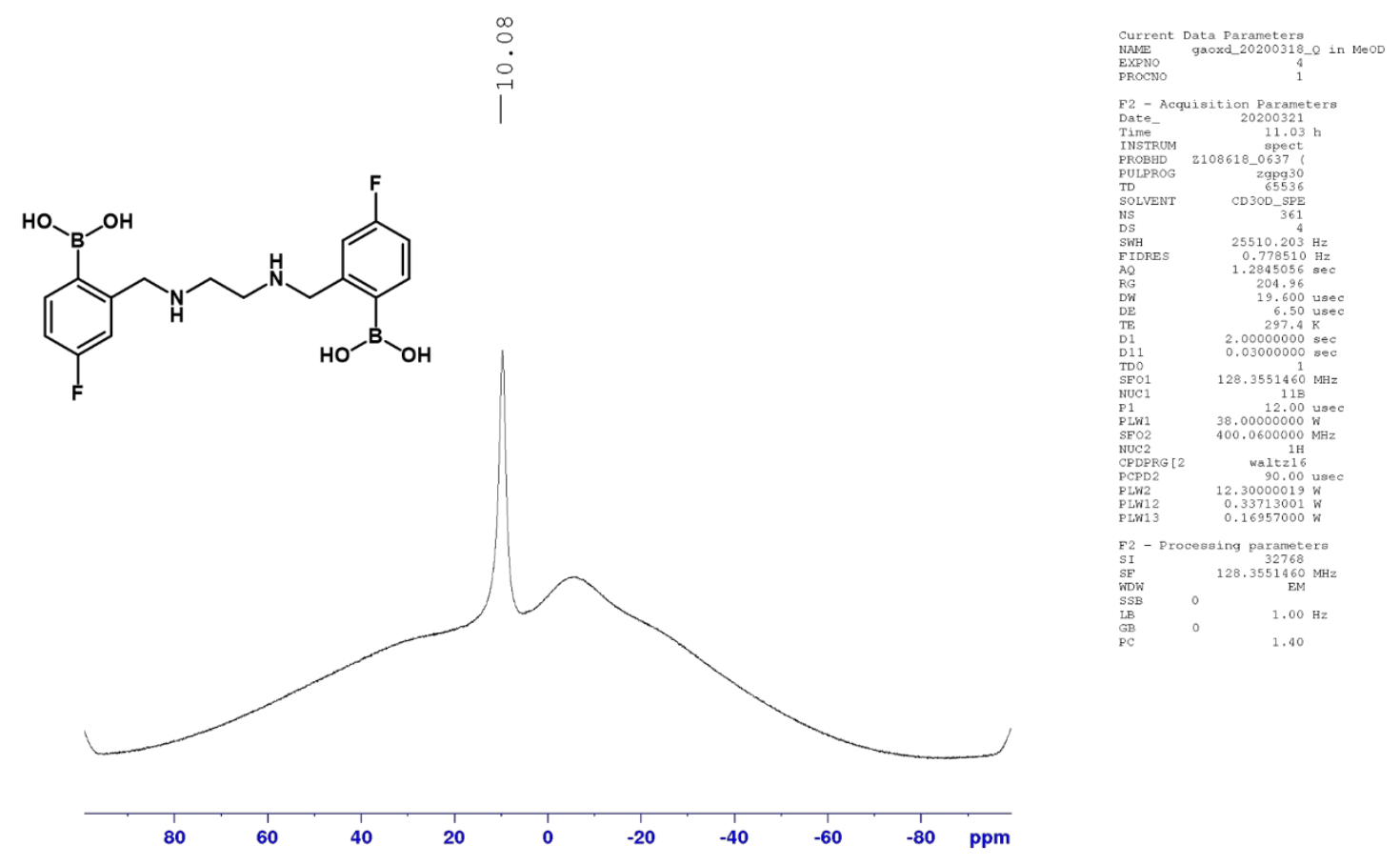

Figure S4. ${ }^{11} \mathrm{~B}$ NMR(128 MHz, MeOD) spectrum of sensor 1

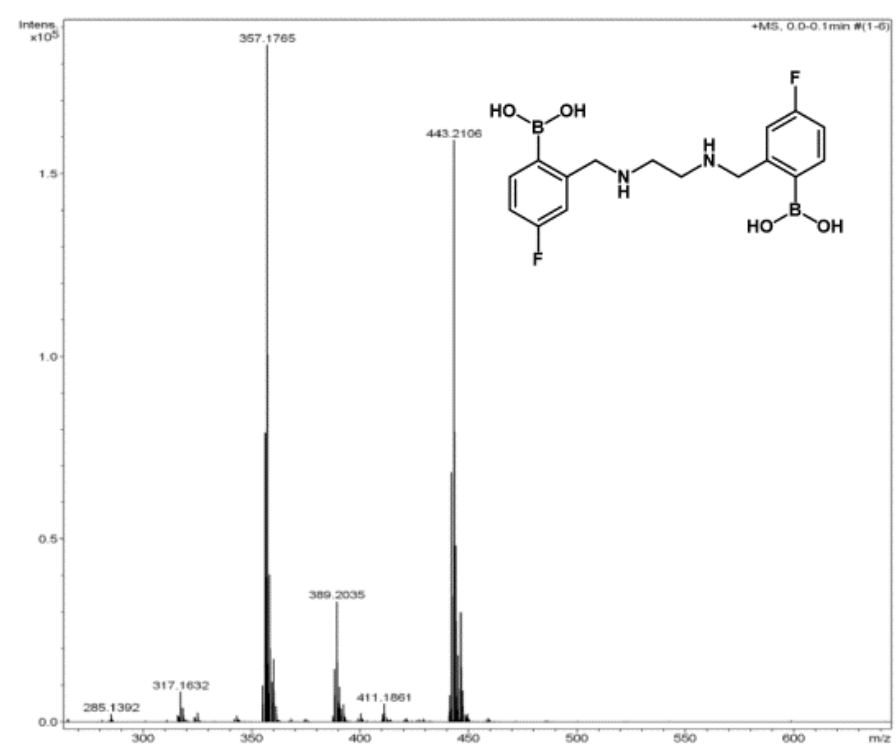

Figure S5. HRMS(ESI +$)$ spectrum of sensor 1, (m/z): $357.1765\left(\mathrm{M}+\mathrm{H}+2 \mathrm{CH}_{3} \mathrm{OH}-2 \mathrm{H}_{2} \mathrm{O}\right.$; Calc: 357.1758). 


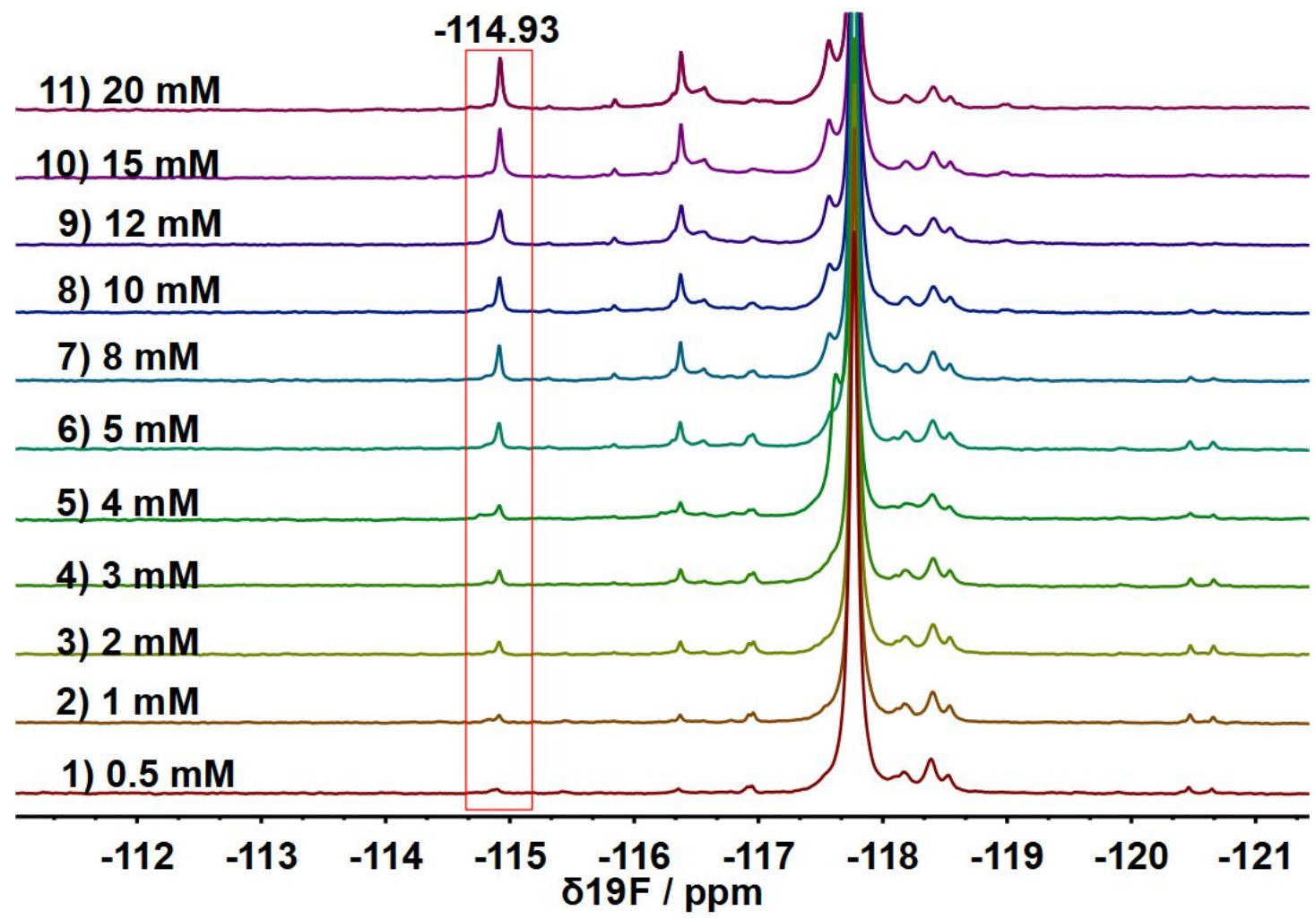

Figure S6 ${ }^{19} \mathrm{~F}$ NMR spectra of sensor $1\left(10 \mathrm{mM}\right.$, ethanol containg $10 \% \mathrm{D}_{2} \mathrm{O}(\mathrm{v} / \mathrm{v})$ and $2 \mathrm{mM}$ $\mathrm{NaOH})$ at $\delta_{19 \mathrm{~F}}-114.93 \mathrm{ppm}$ after different concentration of glucose in human urine addition for $6 \mathrm{~h}$. 